\title{
O uso de antidepressivos na adolescência e sua automedicação
}

\author{
The use of antidepressants in adolescence and their self-medication
}

El uso de antidepresivos em la adolescencia y su automedicación

\section{Resumo}

Introdução: Durante o passar dos anos a depressão vem crescendo cada vez mais em meio a sociedade e afetando as faixas etárias de idade como adolescentes, adultos e idosos. A depressão é um transtorno psiquiátrico que pode causar vários sintomas indesejados. O seu tratamento é realizado por meio de antidepressivos, e sua automedicação pode causar problemas sérios ao usuário como dependências e efeitos não desejados. Objetivo: verificar quais as principais características de uso de antidepressivos na adolescência e sua automedicação como também um dos principais motivos que ocasiona a depressão na adolescência. Metodologia: Os dados foram coletos a partir das bases cientificar online EBSCO, Science Direct e SCIELO. Os descritores utilizados foram: Automedicação, Automedicação na adolescência, Depressão e consequência dos antidepressivos. Como critérios de inclusão foram selecionados 30 artigos publicados entre os anos de 2010 e 2021. Os artigos que não atenderam aos critérios de inclusão, não foram utilizados para a construção do artigo. Conclusão: Torna-se importante a realização desse trabalho como forma de identificar os antidepressivos mais usados pelos adolescentes e os riscos causados pela prática da automedicação. Durante a pesquisa foi possível observa as dos principais medicamentos prescritos para adolescentes com depressão e o Fluoxetina e em seguida vem as medicações amitriptilina, venlafaxina, paroxetina, sertralina e citalopram, sendo assim para incentivar a realização de mais pesquisas sobre o assunto, visto que o assunto não e devidamente amplo, sendo a depressão uma psicopatologia não tão fácil a ser diagnosticada e tão relevante atualmente na sociedade.

Palavras-chave: Adolescentes; Depressão; Automedicação; Antidepressivos; Psicopatologia.

\begin{abstract}
Introduction: Over the years, depression has been growing more and more in society and affecting age groups such as adolescents, adults, and the elderly. Depression is a psychiatric disorder that can cause several unwanted symptoms. Its treatment is carried out by means of antidepressants, and self-medication can cause serious problems to the user, such as dependence and unwanted effects. Objective: To verify the main characteristics of the use of antidepressants in adolescence and its self-medication as well as one of the main reasons that cause depression in adolescence. Methodology: The data were collected from the scientific online databases EBSCO, Science Direct and SCIELO. The descriptors used were: Self-medication, Self-medication in adolescence, Depression and consequence of antidepressants. As inclusion criteria, 30 articles published between the years 2010 and 2021 were selected. The articles that did not meet the inclusion criteria were not used for the construction of the article. Conclusion: This study is important to identify the antidepressants most commonly used by adolescents and the risks caused by the practice of self-medication. During the research, it was possible to observe that the main drugs prescribed for adolescents with depression are Fluoxetine and then the medications amitriptyline, venlafaxine, paroxetine, sertraline and citalopram, thus to encourage more research on the subject, since the subject is not properly broad, and depression is a psychopathology not so easy to be diagnosed and so relevant in society today.
\end{abstract}

Keywords: Adolescents; Depression; Self-medication; Antidepressive Agents; Psychopathology. 


\section{Resumen}

Introducción: A lo largo de los años, la depresión ha ido creciendo cada vez más en la sociedad y afectando a grupos de edad como adolescentes, adultos y ancianos. La depresión es un trastorno psiquiátrico que puede causar muchos síntomas no deseados. Su tratamiento se realiza a través de antidepresivos, y su automedicación puede ocasionar graves problemas al usuario, como adicciones y efectos no deseados. Objetivo: verificar las principales características del uso de antidepresivos en la adolescencia y su automedicación, así como uno de los principales motivos que provocan depresión en la adolescencia. Metodología: Los datos se obtuvieron de las bases de datos científicas en línea EBSCO, Science Direct y SCIELO. Los descriptores utilizados fueron: Automedicación, Automedicación en la adolescencia, Depresión y consecuencias de los antidepresivos. Como criterios de inclusión, se seleccionaron 30 artículos publicados entre 2010 y 2021. Los artículos que no cumplieron con los criterios de inclusión no fueron utilizados para la construcción del artículo. Conclusión: Es importante realizar este trabajo como una forma de identificar los antidepresivos más utilizados por los adolescentes y los riesgos que conlleva la práctica de la automedicación. Durante la investigación se pudieron observar los principales fármacos prescritos a adolescentes con depresión y Fluoxetina, seguidos de los medicamentos amitriptilina, venlafaxina, paroxetina, sertralina y citalopram, para así incentivar futuras investigaciones sobre el tema, ya que el tema no es lo suficientemente amplio., , siendo la depresión una psicopatología no tan fácil de diagnosticar y tan relevante hoy en día en la sociedad.

Palabras clave: Adolescentes; Depresión, Automedicación; Antidepresivos; Psicopatología.

\section{Introdução}

Há algum tempo foram feitas algumas pesquisas relacionadas a depressão na adolescência e os perigos que a automedicação traz através da utilização dos antidepressivos. Essas pesquisas relatam que a automedicação pode causar sérias complicações aos adolescentes e crianças. A depressão em jovens vem sendo cada vez mais estudada por cientistas e pesquisadores, tendo em vista o que leva ao jovem ser diagnosticado com depressão ou sintomas depressivos, podendo ser provocados por uma autocobrança, além das cobranças socioeconômicas, como maturidade fora do tempo determinado (Lopes, 2019).

A depressão é um transtorno psiquiátrico que vem afetando a população a décadas e que atinge também a juventude de forma grave. As porcentagens de jovens a cada ano vêm crescendo cada vez mais. Além disso, a automedicação, também é outro problema de agravo, que vem sendo observado nesta população (Horwitz et al, 2010).

Segundo uma pesquisa realizada no ano de 2017, no EUA, cerca de 3,2 milhões de crianças entre as idades de 12 a 17 relataram sintomas de depressão major ou unipolar que tem como definição um transtorno comum onde os sintomas são falta de interesse ou ânimo, tristeza, perda de prazer em realizar atividade, falta de concentração e cansaço durante a adolescência (Lopes, 2019).

Na pesquisa realiza por Campos e colaboradores (2019), em 302 jovens foi observado onde 19,2\% dos adolescentes faziam uso de medicamentos controlados e entre eles 3,6\% eram adolescentes que faziam uso de medicamentos psicotrópicos sendo eles a grande maioria do sexo feminino. Os autores ainda relatam em sua pesquisa sobre os cuidados que devem ser tomados com os psicofármacos podendo causar vários problemas de tolerâncias e dependências.

A Pesquisa que discutem sobre a relação com os cuidados primários contra a depressão, estimam que 2 a cada 3 adolescentes com depressão, não são identificados/diagnosticados como também não recebem tratamento, com isso, dos que são diagnosticados só 50\% deles recebem um tratamento adequado (Brito, 2011).

\section{Metodologia}

Se trata de uma revisão de literatura do tipo narrativa, baseada nos artigos originais e revisões achados em bancos de dados como: EBSCO, Science Direct e SCIELO, descrevendo-os. A revisão aplicada nesse estudo tem como objetivo a busca por informações simultâneas, através da utilização de procedimentos explícitos, visando identificar, analisar e avaliar o maior número de estudos publicados e revisados que tenham contribuição significativa a fim de fornecer informações seguras e qualificadas, tornando estes dados acessíveis para os demais leitores. 
Como critérios de inclusão utilizaram-se artigos originais datados entre 2010 e 2021, como critérios de exclusão, serão descartados trabalhos fora da temática proposta, duplicados e aqueles publicados em anos anteriores ao determinado.

Os dados obtidos foram selecionados através de artigos, livros, documentos, fotos, textos, periódicos, manuscritos e até pela internet, tendo como principal autor base Lopes, C. S., que contribuiu significativamente para a construção deste trabalho. Utilizando diferentes descritores, são eles: Automedicação, Automedicação na adolescência, antidepressivos por Depressão na adolescência, Depressão e consequência dos antidepressivos.

\section{Resultado e Discussão}

Durante a coleta de dados foram analisados 110 artigos, entre todos os artigos que foram analisados e que abordavam o tema sobre a automedicação com antidepressivos na adolescência, foi possível selecionar 30 artigos, logo após a aplicação dos critérios de inclusão e exclusão (Fig. 1), onde foram utilizados para a realização dessa pesquisa. Durante a seleção dos artigos vários critérios foram exigidos para a finalização do trabalho. (Figura 1).

Figura 1. Seleção dos artigos utilizados no desenvolver do trabalho.

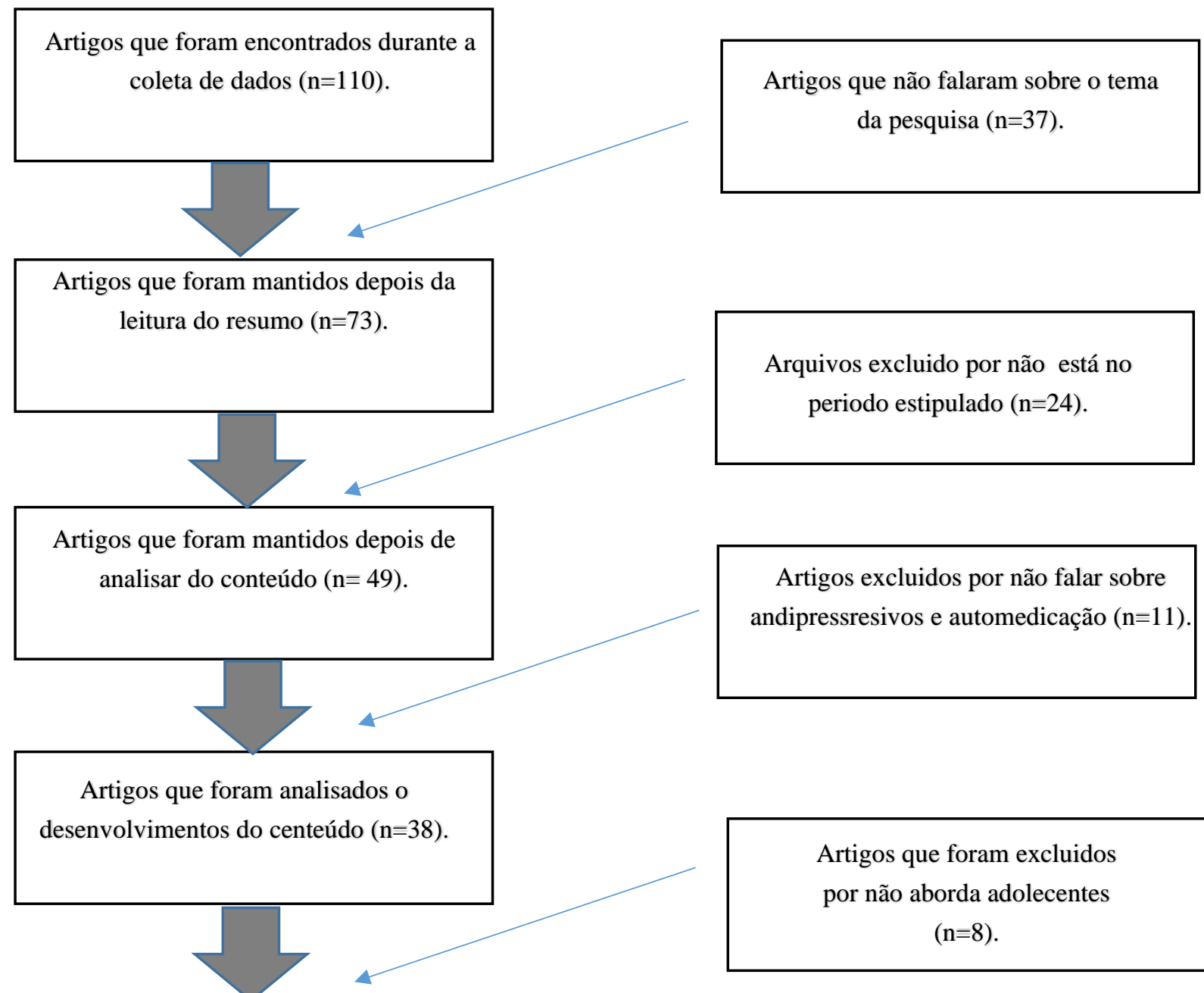

Artigos que foram mantidos para o desenvolvimento da descurção do trabalho $(n=30)$. 
Sendo assim na Figura 1 Através desses artigos analisados, foram coletados dados podendo ser traçado um caminho para mostrar os resultados das pesquisas, com uma base de tempo limitado entre (2010-2021), que tenham conteúdos relacionados com o tema do trabalho e que tenha relação com o objetivo do trabalho realizado.

Para a realização da inclusão dos artigos foi necessário a organização do material de forma específica destacando algumas informações sendo elas: Título do artigo, Tipo de pesquisa, Ano de publicação e objetivos, como descrito na tabela 1.

Tabela 1: Classificação dos artigos selecionados para a utilização como base de referência de orientação do tema central do estudo sobre a utilização dos antidepressivos durante a adolescência.

\begin{tabular}{|c|c|c|c|}
\hline Título & Tipo de pesquisa & $\begin{array}{l}\text { Autor(es)/ano de } \\
\text { publicação }\end{array}$ & Objetivos \\
\hline $\begin{array}{l}\text { Perfil epidemiológico de automedicação entre } \\
\text { acadêmicos de medicina de uma universidade } \\
\text { pública brasileira. }\end{array}$ & $\begin{array}{l}\text { Pesquisa } \\
\text { Descritiva. }\end{array}$ & $\begin{array}{l}\text { Cardoso, H. B.; Costa, F. F.; } \\
\text { Souza, J. C. W.; et al., } 2020 .\end{array}$ & $\begin{array}{l}\text { Descrever a porcentagem de alunos que fazendo uso } \\
\text { de medicamentos sem acompanhamento médico. }\end{array}$ \\
\hline $\begin{array}{l}\text { Uso de antidepressivos por crianças e } \\
\text { adolescentes e o risco de comportamentos } \\
\text { violentos e suicidas. }\end{array}$ & $\begin{array}{l}\text { Pesquisa } \\
\text { Bibliográfica. }\end{array}$ & Lopres, C. S., 2019. & $\begin{array}{l}\text { Descreve como objetivo principal } \\
\text { a conscientização da automedicação voltados aos ado } \\
\text { lescentes e jovens. }\end{array}$ \\
\hline $\begin{array}{l}\text { Depressão em Adolescentes: Revisão da } \\
\text { Literatura e o Lugar da Pesquisa } \\
\text { Fenomenológica. }\end{array}$ & $\begin{array}{l}\text { Revisão } \\
\text { sistemática. }\end{array}$ & $\begin{array}{l}\text { Melo, A. K.; Siebra, A. J., } \\
2017 .\end{array}$ & $\begin{array}{l}\text { Descreve como objetivo relata os } \\
\text { principais sintomas depressivos nos adolescentes. }\end{array}$ \\
\hline $\begin{array}{l}\text { Intensidade de sintomas depressivos em } \\
\text { adolescentes através da escala de depressão de } \\
\text { Beck (BDI-II). }\end{array}$ & $\begin{array}{l}\text { Pesquisa } \\
\text { Descritiva. }\end{array}$ & $\begin{array}{l}\text { Lima, I. I. A.; Bulcão, L. T.; } \\
\text { Sả, A. B.; Femandes, R. M. } \\
\text { L., } 2013 .\end{array}$ & $\begin{array}{l}\text { O objetivo da pesquisa e avaliar os sintomas de } \\
\text { depressão em adolescentes. }\end{array}$ \\
\hline $\begin{array}{l}\text { Depressão nos adolescentes - mito ou } \\
\text { realidade? }\end{array}$ & $\begin{array}{l}\text { Pesquisa } \\
\text { retrospectivo e } \\
\text { analítico. }\end{array}$ & $\begin{array}{l}\text { Resende, C.; Santos, E.; } \\
\text { et al., } 2013 \text {. }\end{array}$ & $\begin{array}{l}\text { Realizar avaliação das características depressivas ent } \\
\text { re os adolescentes e suas constâncias na consulta dos } \\
\text { adolescentes. }\end{array}$ \\
\hline $\begin{array}{l}\text { Conhecimento de adolescentes acerca dos } \\
\text { benefícios do exercício físico para saúde } \\
\text { mental. }\end{array}$ & $\begin{array}{l}\text { Estudo } \\
\text { Transversa. }\end{array}$ & $\begin{array}{l}\text { Campos, C. G.; Muniz, L. A.; } \\
\text { Silva, V. B.; et al., } 2019 .\end{array}$ & $\begin{array}{l}\text { O objetivo da pesquisa e orientar os adolescentes sob } \\
\text { re os beneficios do exercício fisico para } \\
\text { a saúde mental. }\end{array}$ \\
\hline $\begin{array}{l}\text { Suicídio na adolescência: fatores de risco, } \\
\text { depressão e gênero. }\end{array}$ & $\begin{array}{l}\text { Pesquisa } \\
\text { Bibliográfica. }\end{array}$ & $\begin{array}{l}\text { Braga, L. L.; Dalbosco, D.A., } \\
2013 .\end{array}$ & $\begin{array}{l}\text { O objetivo da pesquisa e discutir fatores } \\
\text { e aspectos que leva ao suicídio na adolescência como } \\
\text { também destacar gênero e a depressão. }\end{array}$ \\
\hline $\begin{array}{l}\text { Transtorno de estresse pós-traumáticos } \\
\text { (TEPT) na infància e na adolescência: } \\
\text { prevalência, diagnóstico e avaliação. }\end{array}$ & $\begin{array}{l}\text { Pesquisa } \\
\text { Bibliográfica. }\end{array}$ & $\begin{array}{l}\text { Borge, J. L.; Zoltowsk, A. P. } \\
\text { C.; et al., } 2010 .\end{array}$ & $\begin{array}{l}\text { O objetivo da pesquisa tem como relatar todos } \\
\text { os TEPT Transtomo de Estresse Pós-Traumático } \\
\text { na adolescência e infância. }\end{array}$ \\
\hline $\begin{array}{l}\text { As possíveis consequências do abuso sexual } \\
\text { praticado contra crianças e adolescentes. }\end{array}$ & $\begin{array}{l}\text { Pesquisa } \\
\text { Bibliográfica. }\end{array}$ & Ricardo, B. B. F., 2015. & $\begin{array}{l}\text { A pesquisa tem como objetivo sistematizar como } \\
\text { contribuição teórica para divulgação e divulgar o } \\
\text { conhecimento sobre as possíveis consequências de } \\
\text { abusos sexuais na adolescência. }\end{array}$ \\
\hline
\end{tabular}

Fonte: Autores (2020).

Em seguida a coleta e revisão dos artigos selecionados na tabela 1, observando os seus objetivos foi visto uma semelhança entre eles e o tema central desse estudo. Sendo assim o principal objetivo desse estudo foi relatar quais os principais motivos 
para a realização da automedicação e consumo irregular de antidepressivos entre os adolescentes e seus efeitos colaterais, como também os principais indícios de depressão durante a fase da adolescência.

Com isso foram projetados tópicos para relata a as principais consequências do uso de antidepressivos sem acompanhamento médico e principalmente o que pode levar ao adolescente adquirir sintomas depressivos.

\subsection{Traumas na adolescência}

Os Transtornos do Estresse Pós-Traumáticos (TEPT) citados na pesquisa de Borges e colaboradores (2010), relatam os tipos de traumas que podem afetar o adolescente e por quais motivos são provocados tais traumas, sendo eles por diversos motivos: autocobrança, perca de um parente próximo, sensação de abandono, abuso sexual, sentimento de negação, angústia, exclusão, entre outros fatores, sendo isso uma porta para a entrada da depressão na vida do adolescente.

Com isso, Florentino, et al., (2015), descreve que a TEPT acontece por experiência em momentos incomuns que consequentemente pode causar traumas a um indivíduo deixando sequelas mentais e físicas. $\mathrm{O}$ mesmo autor, ainda fala sobre $\mathrm{o}$ abuso sexual em adolescentes relatando que tais atos podem causar em um adolescente traumas irreversíveis. Além disso, considera-se abuso sexual quando um ou mais adultos tem a intensão sexual em um adolescente ou jovem, podendo ser membros da própria família ou pessoas que não tem parentesco.

Sendo assim, foi relatado por De Lima Braga e colaboradores, em 2013, que o maior índice de suicídio durante a adolescência é do sexo feminino e que os fatores relacionados são: isolamento social, abandono, uso de álcool entre outros. No seu estudo, ainda mostra que a depressão na adolescência se manifesta durante um longo tempo, sendo ele causador de consequências sociais e podendo ocorrer até a vida adulta.

A pesquisa realizada por Cerutti, et al, (2019), apresenta que de 71 adolescentes sendo eles meninos e meninas de 8 aos 14 anos, sendo eles da maioria do sexo feminino. $40,85 \%$ deles apresentaram um comportamento suicida e 36,6\% apresentaram um comportamento de automutilação.

\subsection{Depressão em adolescentes}

Todo ser humano está exposto a algum tipo de estresse ou um momento de emoção desagradável. A depressão acontece cada vez mais na adolescência, geralmente ocasionada por algum tipo de trauma podendo ser: baixa estima, falta de interesse, cobrança de si mesmo, entre outros. Assim, a depressão, é considerada uma doença cada vez mais comum durante essa faixa etária (10 a 18), portando trazendo consequências que podem afetar a vida adulta podendo ser um estopim para o desencadeamento de futuras doenças (Melo, et al., 2017).

Durante a adolescência existem vários fatores que podem levar a essa patologia, devido ao fato de que esses adolescentes pretendem se enquadrar no seu meio social e como também realizar possíveis relacionamentos durante esse tempo, gerando neles uma grande quantidade de sentimentos de desconfiança, medo e aflição. $O$ autor ainda fala que nessas perspectivas do adolescente pode afetar a autoconfiança do jovem, causando vários danos de autoestima e sendo até comparado a um "superherói” rejeitado e maltratado (Ribeiro, et al 2010).

Na pesquisa realizada por Resende e colaboradores, 2013, foi visto que os atendimentos primários realizados na área pediátrica têm uma colocação de linha de frente para os diagnósticos da depressão em adolescentes, sendo eles um alvo difícil para realizar uma conversa aberta. Os autores também falam sobre a importância de programas sociais com famílias de adolescentes nas comunidades, sendo eles de baixa renda como também os com uma renda alta, podendo ter um acesso melhor aos adolescentes, sendo os profissionais na área áreas de Psicologia, Pedagogia, Psicopedagogia e Serviço Social.

Miranda e colaboradores (2013), demonstram a importância dos Educadores escolares na linha de frente contra a depressão na adolescência, vendo que os educadores escolares têm um contato mais direto e diário com os jovens. Nessa mesma pesquisa 
mostra que adolescentes que tem descendência genética familiar depressiva, como a dos pais, tem uma probabilidade de três vezes mais de adquirir depressão, pelo fato da criança interpretar seus pais como espelho de padrão a ser seguido, sendo uma atitude realizada normalmente pelas crianças levando-a ter sintomas depressivos genéticos.

Em uma pesquisa de campo, realizada com 88 adolescentes, sendo 44 do sexo masculino e 44 do sexo feminino, sendo eles da idade de 12 aos 17 anos de escolas públicas e particulares. Nessa pesquisa, foi observado que de 88 adolescentes, 43 tem sintomas leve de depressão e 2 com casos graves, relatado também nessa pesquisa que entre os adolescentes com depressão, a maior parte são aqueles que apresentam maiores números de problemas e menor é o nível de suporte familiar, além de maior consumo de drogas ilícitas, vendo assim a importância da família e do apoio aos adolescentes (De Lima Argimon, et al, 2013).

\subsection{Automedicação}

A automedicação é uma prática caracterizada fundamentalmente pela iniciativa de um doente, ou de seu responsável, em utilizar um produto que acredita lhe trazer benefícios no tratamento da doença ou alívio de sintomas, desse modo, as orientações médicas são deixadas de lado e o paciente passa a utilizar medicações indicadas por pessoas não autorizadas, entre estas: familiares, amigos ou até mesmo balconistas em farmácias. Outra forma de automedicação seria a reutilização de receitas médicas anteriores, mesmo que o uso contínuo do medicamento não tenha sido especificado (Matos et al, 2018).

O resultado dessa busca de saúde de forma rápida tem como principal consequência, um aumento nos índices de efeitos negativos advindos do uso inadequado de tais substâncias. Sendo assim, é importante ressaltar que fatores econômicos, políticos e culturais têm contribuído expressivamente para o crescimento e a difusão da utilização inadequada e irresponsável de medicamentos, tanto no Brasil quanto no mundo, tornando um problema de saúde pública (De Araújo et al, 2019).

A automedicação, embora objetive o bem-estar físico e mental de quem a utiliza, pode trazer várias reações adversas como o aumento de resistência bacteriana, hemorragia, alergia, intoxicação, doenças iatrogênicas, efeitos indesejáveis, mascaramento de doenças etc. Estudos apontam que esta prática é adotada por inúmeras pessoas da sociedade, e atinge todas as faixas etárias, níveis educacionais e sociais, devendo a educação em saúde ser a estratégia impulsionadora para a capacitação do uso racional e correto dos medicamentos (Dos Santos et al, 2019).

Alguns grupos são mais vulneráveis a esse tipo de exposição a medicamentos, como por exemplo os adolescentes, que estão na faixa etária entre 12 a 18 anos de idade. Uma pesquisa realizada em uma cidade no sul do Brasil, constatou que a frequência de automedicação em população adolescente escolar varia de 12\% a 36\%, e chama atenção para a gravidade associada ao consumo irracional de medicamentos, pelo fato de que essas substâncias eram consumidas simultaneamente com algum tipo de droga ilícita. Outro fator importante é que, nesta fase da vida, as mães contribuem bastante para essa automedicação, pela influência que exerce no comportamento do adolescente, atitude que acarretar consequências graves a saúde, visto que não há conscientização sobre esses riscos ou eles são negligenciados (Pereira et al, 2019).

\subsection{Efeitos colaterais da automedicação}

O uso descontrolado dos medicamentos antidepressivos pode ser potencialmente nocivo à saúde individual e coletiva. O uso inadequado e avulso de substâncias e até mesmo de fármacos considerados "simples" pela população, como os analgésicos, pode ocasionar diversas consequências como resistência bacteriana, hipersensibilidade, dependência, sangramento digestivo, sintomas de retirada e ainda aumentar o risco para determinadas neoplasias (Ribeiro et al, 2010).

As queixas que mais frequentemente se associam a prática da automedicação são derivadas do sistema nervoso central e dos aparelhos respiratório e digestivo, como por exemplo: cefaleia, dores musculoesqueléticos, febre, infecções respiratórias, pirose, dor abdominal, constipação e diarreia (Furtado et al, 2019). 
O uso de medicações como anti-inflamatórios, analgésicos, antibióticos, antialérgicos e antidepressivos sem a indicação médica, podendo ser influenciado por pessoas do cotidianas, vem sendo cada vez mais comum no dia a dia, causando cada vez mais sintomas indesejáveis como ânsia de vomito, mal-estar, reação alérgica podendo ser adquirido até chegar a um estado grave, como por exemplo o mal uso de antibióticos levando-o ao favorecimento do surgimento de novas cepas bacterianas, conhecidas por "superbactéria". Vendo isso, Fonseca e colaboradores (2010), em sua pesquisa em universitários com 299 participantes foi visto que 97,4\% dos participantes afirmaram a importância do uso de antibióticos segundo a prescrição médica, como também foi observado que entre eles 36,7\% realizavam uso segundo a prescrição médica, então 63,3\% dos participantes não realizam a terapia corretamente segundo a prescrição médica.

O consumo de medicamentos sem uma orientação médica pode tratar os sintomas indesejados pelo paciente no momento da automedicação, como também pode mascarar os sintomas e até ser confundido com a doença, os sintomas onde o paciente gostaria de tratar acabaria agravando, em casos mais severos, o paciente pode apresentar evolução do quadro patológico e ser hospitalizado (Telles Filho et al, 2013).

Na pesquisa realizada por, Valença e colaboradores, 2020, foi relatado que a utilização de antidepressivos com imprudência pode causar efeitos de dependências tóxicas aos jovens, visto por ele que, muitas vezes o jovem faz uso indevido dos psicotrópicos por não conseguir lidar com as aflições do dia a dia utilizando a medicação como uma fuga da realidade onde está inserido.

Em uma pesquisa realizada em uma Universidade Federal de Jataí, com os estudantes de medicina, foi observado que entre os estudantes os antidepressivos estão em segundo lugar diante das medicações de uso sem orientação medica, podendo levar a dependência química e logo em seguida os antibióticos, onde foi visto que é um dos principais fatores da resistência bacteriana e pela dificuldade de seguir com o protocolo de tratamento interrompendo-o como até mesmo fazendo o uso de apenas uma dose da medicação sem seguir a posologia (Bernardes et al, 2020).

\subsection{Antidepressivos mais utilizados por automedicação pela população jovem}

A utilização de fármacos psicoativos faz parte da natureza humana, visando alterar o comportamento, humor e emoções, modificando o comportamento normal e produzindo estados alterados de sentimentos com propósitos religiosos, cerimoniais ou recreacionais e para alívio de enfermidades mentais. Os fármacos psicotrópicos podem ser definidos como aqueles que agem alterando o humor e o comportamento, fazendo com que a comunicação entre os neurônios sofra uma mudança, podendo produzir diversos efeitos de acordo com o tipo de neurotransmissor envolvido e a forma como a droga atua. Assim, de acordo com o tipo de ação, as drogas podem provocar euforia, ansiedade, sonolência, alucinações, delírios etc. A ação de cada fármaco depende de sua classe, da via de administração, da quantidade, do tempo, da frequência de uso, da absorção e eliminação pelo organismo e da sua interação com outros fármacos (Magalhães et al, 2016).

O aumento do uso de antidepressivos, nesta década, está ligada ao surgimento de novas medicações, ampliando as indicações terapêuticas, e com o crescimento descontrolado do diagnóstico de doenças depressivas na população em geral, principalmente entre os jovens (Ribeiro et al, 2014).

Os antidepressivos mais usados entre adolescentes segundo uma pesquisa realizada no ano de 2020 são: Fluoxetina, amitriptilina, venlafaxina, paroxetina, sertralina e citalopram. Entre eles o mais utilizado é a fluoxetina que pertence a uma classe de Inibidores seletivos da recaptação da serotonina (ISRS), que tem sua atuação diretamente no sistema nervoso central, aumentando os níveis de serotonina produzida pelo corpo, ocasionando o bem-estar, o aumento do apetite e melhorando a sonolência. A fluoxetina é uma medicação que pode ser encontrada em suas formas farmacêuticas de gotas e cápsulas. Sendo a amitriptilina a segunda mais utilizadas que pertence a uma classe de antidepressivo diferentes dos demais, pertencendo assim a classe dos Antidepressivo Tricíclico (ADTs) A pesquisa foi realizada com 110 pacientes onde entre eles foram observados que 
os percentuais de medicamentos mais prescritos eram de Fluoxetina (41\%) Amitriptilina (17\%) Venlafaxina (14\%) Paroxetina (11\%) Sertralina (8\%) Outros medicamentos (10\%) (Figura 2). (Da Silva Barbosa et al, 2020).

Figura 2. Percentual de medicamentos mais prescrito em casos de depressão na adolescência.

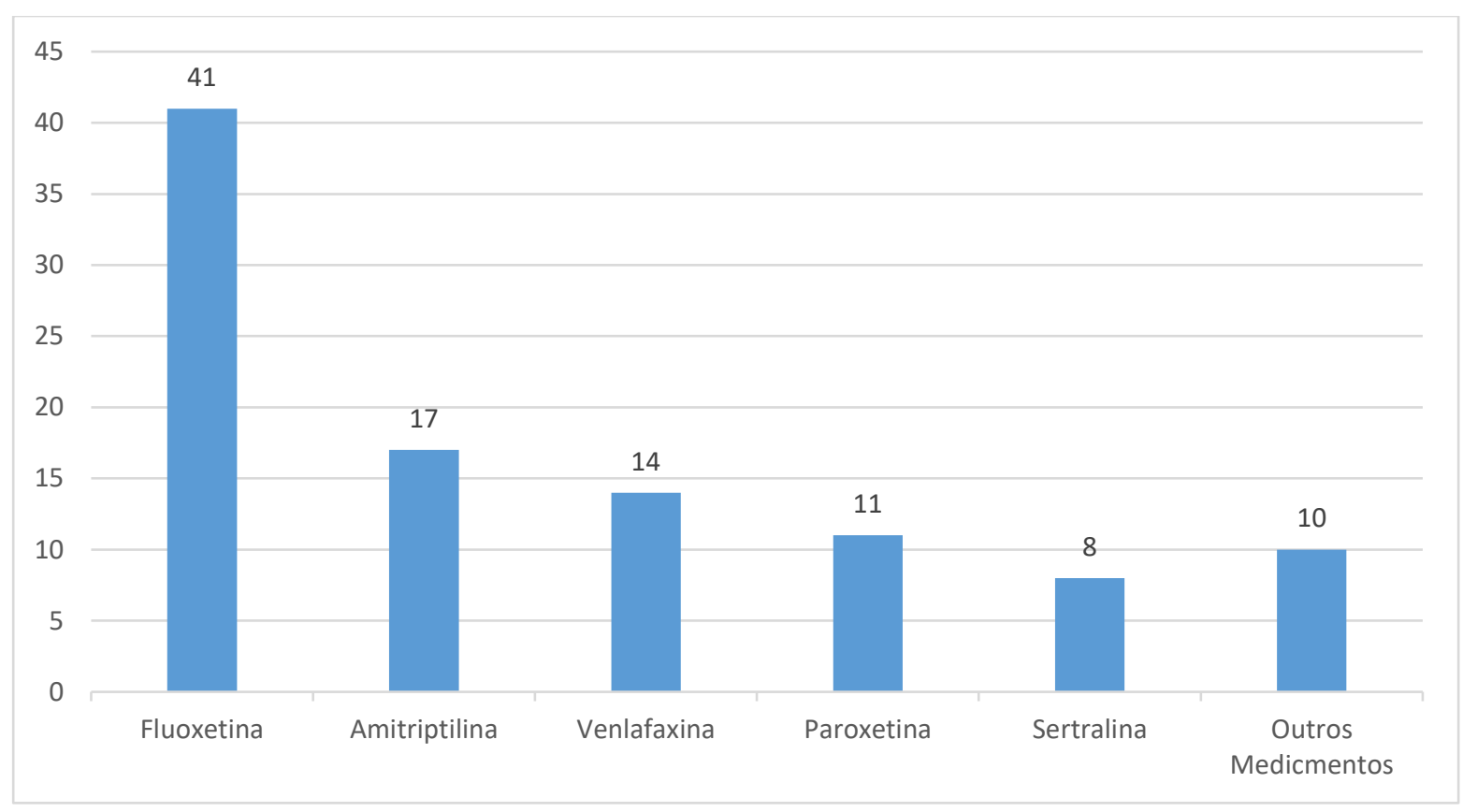

Fonte: Silva Barbosa et al. (2020).

Na Figura 2 observe-se o percentual de cada medicação que são prescritas por médicos para adolescentes que tem indícios depressivos e observa-se que a fluoxetina e a medicação mais utilizadas entre elas.

\subsection{Inibidores seletivos da recaptação da serotonina (ISRS)}

A classe de antidepressivos mais utilizados para o tratamento com adolescentes são os Inibidores Seletivos da Recaptação da Serotonina (ISRS) que são eles: Fluoxetina, Paroxetina, Sertralina, Venlafaxina e Citalopram. Ao iniciar o tratamento, os ISRS têm uma grande atração pelos transportadores seletivos da serotonina, acontecendo assim, um aumento considerado da concentração dessa substância na fenda sináptica, caracterizando um tratamento a curto prazo, em pouco tempo os níveis de serotonina diminuem, entretanto com esse curto prazo de aumento da serotonina na fenda sináptica, é possível estimular os receptores pré-sinápticos, promovendo um aumento significativo da concentração na fenda sináptica. Entretanto a serotonina, depois dos estímulos nervosos, aumenta junto com as ligações dos receptores pós-sinápticos, dando assim a resposta do antidepressivo demonstrando seletividade na relação de captação do 5-HT (De Sousa Paulino, 2018). Os inibidores seletivos da recaptação da serotonina (ISRS) são considerados entre os antidepressivos, o que provocam mais efeitos colaterais sendo eles sinusite, faringite, sintomas gripais, insônia, dor de cabeça, fadiga, náuseas e diarreia.

\subsection{Antidepressivo Tricíclico (ADTs)}

Uma das alternativas mais utilizada também no meio clinico são os antidepressivos tricíclicos (ADTs) sendo um deles a amitriptilina. Durante a administração de antidepressivo tricíclico em níveis pré-sinápticos, eles realizam o bloqueio dos receptores de monoamanias sendo assim bloqueados norepinefrina as serotoninas como também em baixa porcentagem 
dopaminas no organismo. A atividade pós-sináptica altera de acordo com o sistema neutronasmissor envolvido e também e geralmente responsável pelos efeitos colaterais no usuário. Os antidepressivos tricíclicos são bloqueadores de receptores muscarinas histaminérgicos de tipo 1 , a 2 e $\beta$-adrenérgicos, serotonérgicos sendo também dificilmente bloqueador de dopaminérgicos. (Silva et al, 2014). Um dos efeitos colaterais mais comuns durante a utilização da amitriptilina e boca seca, sonolência, dificuldade na contração, tontura entre outros.

\section{Conclusão}

Dessa forma, pode-se afirmar que a depressão na adolescência é uma das principais patologias adquiridas pelos jovens, visto que entre 4 adolesceste 1 e acometida por sintomas depressivo, sendo um problema grave de saúde, associado a vários fatores relacionados principalmente ao meio em que o adolescente vive. A automedicação com antidepressivos se tornou um hábito comum, trazendo inúmeros preocupantes a respeito desse assunto para a saúde pública. As medicações mais consumidas sem prescrições medicas são Fluoxetina, Paroxetina, Sertralina, Venlafaxina e Citalopram que podem levar ao usuário a dependência como também sonolências, tonturas, fadiga entre outros sintomas

Portanto, fez-se necessário a elaboração desse estudo, como forma de esclarecer os antidepressivos mais usados pelos adolescentes e os riscos causados pela prática da automedicação.

Por se tratar de um tema que causa grande impacto na saúde do adolescente e por não ter um diagnóstico fácil, é necessário a elaboração de mais artigos que abordem este assunto, pois o número de artigos disponíveis que expõe sobre tal relação não é devidamente amplo. Diante disso, nota-se uma falta de estudos que mostrem a eficácia do tratamento, os riscos causados pela prática da automedicação e as principais causas que levam a tal prática, a fim de proporcionar mais esclarecimento a população e colaborar com os profissionais de saúde.

\section{Referências}

Bernardes, H. C., Costa, F. F., Wanderley, J. C. S., de Farias, J. P., Liberato, L. S., \& de Moura Villela, E. F. (2020). Perfil epidemiológico de automedicação entre acadêmicos de medicina de uma universidade pública brasileira. Brazilian Journal of Health Review, 3(4), 8631-8643.

Borges, J. L., Zoltowski, A. P. C., Zucatti, A. P. N., \& Dell’Aglio, D. D. (2010). Transtorno de estresse pós-traumático (TEPT) na infância e na adolescência: prevalência, diagnóstico e Avaliação. Avaliação Psicológica, 9(1), 87-98.

Brito, I. (2011). Ansiedade e depressão na adolescência. Revista Portuguesa de Medicina Geral e Familiar, 27(2), $208-14$.

Campos, C. G., Muniz, L. A., Belo, V. S., Romano, M. C. C., \& Lima, M. D. C. (2019). Conhecimento de adolescentes acerca dos benefícios do exercício físico para a saúde mental. Ciência \& Saúde Coletiva, 24, 2951-2958.

Cerutti, F., Bastos, A., Marco Salvador, JH, Dullius, AL, \& de Lima Argimon, II (2019). Fatores envolvidos na mudança de comportamento de uso de drogas na adolescência: Estudo de Caso. Revista Brasileira de Terapia Comportamental e Cognitiva, 2019, vol. 21, núm. 1, pág. 118-128 .

Silva Barbosa, E. S., Rodrigues, K. D. S. R., \& de Carvalho Abreu, C. R. (2020). antidepressivos utilizados por adolescentes assistidos no cen-tro de atenção psicossocial (caps ii) em cidade ocidental-go. Revista JRG de Estudos Acadêmicos, 3(7), 329-335.

Araújo, L. K. P., \& de Goes, P. S. A. (2019). Prevalência de automedicação entre adolescentes escolares de 15-19 anos. ANAIS DA FACULDADE DE MEDICINA DE OLINDA, 4(2), 19-24.

Lima Argimon, I. I., Terroso, L. B., de Sá Barbosa, A., \& Lopes, R. F. (2013). Intensidade de sintomas depressivos em adolescentes através da escala de depressão de Beck (BDI-II). Boletim-Academia Paulista de Psicologia.

Lima Braga, L., \& Dell'Aglio, D. D. (2013). Suicídio na adolescência: fatores de risco, depressão e gênero. Contextos Clínicos, 6(1), 2 -14.

Sousa Paulino, P. H. Estudo teórico da fluoxetina.https://www.ufsj.edu.br/portal2-repositorio/File/coqui/TCC/Monografia-TCC-Paulo_H_S_Paulino.pdf

Santos, E. S. P., Andrade, C. M., \& Bohomol, E. (2019). Prática da automedicação entre estudantes de ensino médio. Cogitare Enfermagem, 24.

Florentino, B. R. B. (2015). As possíveis consequências do abuso sexual praticado contra crianças e adolescentes. Fractal: Revista de Psicologia, $27,139-144$.

Fonseca, F. I. R. M. D., Dedivitis, R. A., Smokou, A., Lascane, E., Cavalheiro, R. A., Ribeiro, E. F., ... \& Santos, E. B. D. (2010). Frequência de automedicação entre acadêmicos de faculdade de medicina. Diagn. tratamento. 
Research, Society and Development, v. 10, n. 15, e310101522995, 2021

(CC BY 4.0) | ISSN 2525-3409 | DOI: http://dx.doi.org/10.33448/rsd-v10i15.22995

Furtado, I. T. Automedicação e os seus riscos (Doctoral dissertation).

Horwitz, A. V., \& Wakefield, J. C. (2010). A tristeza perdida: como a psiquiatria transformou a depressão em moda. São Paulo: Summus.

Lopes, C. S. (2019). Relatório de Estágio e Monografia intitulada "Uso de Antidepressivos por Crianças e Adolescentes e o Risco de Comportamentos Violentos e Suicidas" (Doctoral dissertation, Universidade de Coimbra).

Magalhães, J. M., Carvalho, A. D. M. B., Carvalho, S. M., Alencar, D. D. C., Moreira, W. C., \& Parente, A. D. C. M. (2016). Depressão em idosos na estratégia saúde da família: uma contribuição para a atenção primária. Revista Mineira de Enfermagem, 20.

Matos, J. F., Pena, D. A. C., Parreira, M. P., Santos, T. D. C. D., \& Coura-Vital, W. (2018). Prevalência, perfil e fatores associados à automedicação em adolescentes e servidores de uma escola pública profissionalizante. Cadernos Saúde Coletiva, 26, 76-83.

Melo, A. K., Siebra, A. J., \& Moreira, V. (2017). Depressão em adolescentes: revisão da literatura e o lugar da pesquisa fenomenológica. Psicologia: ciência e profissão, 37, 18-34.

Miranda, M. V., Firmo, W. D. C. A., de Castro, N. G., Alves, L. P. L., Dias, C. N., Rêgo, M. M., ... \& Dias, R. S. (2013). Depressão infantil: aspectos gerais, diagnóstico e tratamento. Cadernos de Pesquisa, 101-111.

Pereira, FGF, Carvalho, MRD, Figueiredo, IGDA, Nascimento, DDS, Benício, CDAV, \& Leal, JDV (2019). Automedicação em adolescentes da rede estadual de ensino na cidade de Picos / Piaú.

Resende, C., Santos, E., Santos, P., \& Ferrão, A. (2013). Depressão nos adolescentes-mito ou realidade?. Nascer e Crescer, 22, 145-150.

Ribeiro, A. G., Cruz, L. P. D., Marchi, K. C., Tirapelli, C. R., \& Miasso, A. I. (2014). Antidepressivos: uso, adesão e conhecimento entre estudantes de medicina. Ciência \& Saúde Coletiva, 19, 1825-1833.

Ribeiro, K. C. S., Coutinho, M. D. P. D. L., \& Nascimento, E. D. S. (2010). Representação social da depressão em uma Instituição de Ensino da Rede Pública. Psicologia: ciência e profissão, 30, 448-463.

Ribeiro, M. I., Oliveira, A., Silva, H., Mendes, M., Almeida, M., \& Silva, T. (2010). Prevalência da automedicação na população estudantil do Instituto Politécnico de Bragança. Revista portuguesa de saúde pública, 28(1), 41-48.

Silva, J. R., de Sousa, M. C., \& Pinto, I. B. (2014). O Consumo de Amitriptilina e Nortriptilina no Hospital Espírita Psiquiátrico de Anápolis. Ensaios e Ciência C Biológicas Agrárias e da Saúde, 18(1).

Telles Filho, P. C. P., \& Pereira Júnior, A. D. C. (2013). Automedicação em crianças de zero a cinco anos: fármacos administrados, conhecimentos, motivos e justificativas. Escola Anna Nery, 17, 291-297.

Valença, R. C. P., Guimarães, S. B., \& da Paixão Siqueira, L. (2020). Prescrição e uso de antidepressivos em crianças e adolescentes-uma revisão da literatura. Brazilian Journal of Development, 6(12), 94860-94875. 